Artigo

\title{
Análise das disciplinas para o ensino da matemática nos cursos de Pedagogia nas instituições públicas de Mato Grosso do Sul
}

\author{
Analysis of disciplines for teaching Mathematics in Pedagogy courses in public institutions \\ in Mato Grosso do Sul
}

\section{Análisis de asignaturas para la enseñanza de las Matemáticas en los cursos de Pedagogía en instituciones públicas del Mato Grosso do Sul}

\author{
Rosemary Borin Cavalheiro ${ }^{1}$ \\ [0000-0003-2753-1568] \\ Edvonete Souza de Alencar ${ }^{2}$ \\ [0000-0002-5813-8702] \\ Silvia Regina da Silva Cassimiro 3 \\ [0000-0003-0966-4383]
}

\section{Resumo}

Este texto tem como proposta de discussão a formação do pedagogo para o ensino de Matemática. Esta reflexão busca responder a seguinte questão: Quais e como são as disciplinas para o ensino da Matemática nas instituições públicas de Mato Grosso do Sul? O objetivo foi identificar as disciplinas de e para o ensino da Matemática. Tomando como referencial metodológico as abordagens qualitativas interpretativas, utilizou para a coleta de dados, a análise documental de todos os PPCs dos cursos de Pedagogia das Universidades Públicas do referido estado. Os resultados da pesquisa apontaram lacunas nos programas de formação inicial dos pedagogos na área da Matemática, principalmente em relação à carga horária das disciplinas e a apropriação insuficiente dos conteúdos matemáticos a serem ensinados. Desta forma, torna-se determinante elevar a qualidade dos cursos de Pedagogia para que o pedagogo adquira conhecimentos sólidos que se convergem na melhoria da qualidade das aprendizagens matemáticas dos alunos.

Palavras-chave: Formação inicial. Educação Matemática. Pedagogia.

\begin{abstract}
This text has as a discussion proposal the formation of the pedagogue for the teaching of Mathematics. This reflection seeks to answer the following question: : What and how are the subjects for teaching Mathematics in public institutions in Mato Grosso do Sul? The objective was to identify the disciplines of and for the teaching of Mathematics. Taking as a methodological reference the interpretive qualitative approaches, used for data collection, the documental analysis of all PPCs of the Pedagogy courses of the Public Universities of that state. The research results pointed out gaps in the programs

\footnotetext{
1 roseborincavalheiro@gmail.com, Mestranda em Educação científica e Matemática pela UEMS, Professora de Educação Infantil, Prefeitura de Dourados, Dourados/Mato Grosso do Sul/Brasil.

2 edvonetealencar@ufgd.edu.br, Doutora em Educação Matemática pela PUC-SP, Professora do Magistério Superior, Universidade Federal da Grande Dourados, Dourados/Mato Grosso do Sul/Brasil.

3 silviamullerddo@hotmail.com, Mestranda em Educação científica e Matemática pela UEMS, Professora de Educação Infantil, Prefeitura de Dourados, Dourados/Mato Grosso do Sul/Brasil.
} 
of initial formation of pedagogues in the area of Mathematics, mainly in relation to the workload of the subjects and the insufficient appropriation of the mathematical contents to be taught. In this way, it becomes crucial to raise the quality of Pedagogy courses so that the pedagogue acquires solid knowledge that converge in improving the quality of students' mathematical learning.

Keywords: Initial training. Mathematics Education. Pedagogy.

\section{Resumen}

Este texto tiene como propuesta de discusión la formación del pedagogo para la enseñanza de las Matemáticas. Esta reflexión busca dar respuesta a la siguiente pregunta: : ¿Cuáles y cómo son las asignaturas para la enseñanza de las matemáticas en las instituciones públicas de Mato Grosso do Sul? El objetivo fue identificar las disciplinas de y para la enseñanza de las Matemáticas. Tomando como referencia metodológica los enfoques interpretativos cualitativos, utilizados para la recolección de datos, el análisis documental de todos los PPC de los cursos de Pedagogía de las Universidades Públicas de ese estado. Los resultados de la investigación señalaron vacíos en los programas de formación inicial de pedagogos en el área de Matemáticas, principalmente en relación a la carga de trabajo de las asignaturas y la inadecuada apropiación de los contenidos matemáticos a impartir. De esta manera, se vuelve crucial elevar la calidad de los cursos de Pedagogía para que el pedagogo adquiera conocimientos sólidos que converjan en la mejora de la calidad del aprendizaje matemático de los estudiantes.

Palabras claves: Formación inicial. Educación Matemática. Pedagogía.

\section{Considerações iniciais}

A formação de professores passou por avanços significativos a partir da Lei de Diretrizes e Bases da Educação Brasileira (LDB) no 9394/96 que exige a formação em nível superior para todas as licenciaturas. Porém, como aponta Tanuri (2000), ainda há muito que avançarmos. Segundo o autor, houve nas últimas décadas pouco avanço qualitativo na formação docente. Para Tanuri (2000, p.85): “O mais grave é que as falhas na política de formação se faziam acompanhar de ausência de ações governamentais adequadas pertinentes à carreira e à remuneração do professor". Menciona que este fato faz refletir na desvalorização social da profissão, o que ocasiona problemas na qualidade de ensino.

Desta forma torna-se determinante darmos importância à qualidade na formação de professores, pois, no cotidiano escolar o pedagogo enfrenta situações que necessitam de preparo no campo teórico-investigativo. Pois, conforme Libâneo (2002), a Pedagogia é uma ciência que procura estudar o contexto educacional em sua totalidade e acrescenta que esta graduação se ocupa do estudo da educação e da prática educativa concreta. Neste contexto, investiga os objetivos sociopolíticos e os meios organizacionais e metodológicos para viabilizar os processos formativos no qual se apoia nas ciências da educação.

Neste contexto, podemos perceber que a Pedagogia deve ir além dos estudos de metodologias e procedimentos, uma vez que a prática do professor revela a transmissão e a mobilização de saberes, teorias e conhecimentos. Desta forma, teoria e prática se convertem em uma conexão circular.

A compreensão de que o professor deve exercer um papel social na formação do cidadão consciente de direitos e práticas de seus deveres, perpassa pela formação inicial a 
partir de conhecimentos científicos e filosóficos, conhecimentos específicos da atividade docente e conhecimentos técnico-profissionais. Desta forma, é relevante ressaltar a necessidade dos cursos de Pedagogia evidenciarem o quê ensinar, o para que ensinar e o como ensinar na mesma proporção, no sentido de desenvolver saberes necessários à incorporação na vida contemporânea e ao exercício da profissão do pedagogo. O processo de formação do pedagogo deve acompanhar as mudanças que ocorrem na estrutura do conhecimento e nos processos de ensino e aprendizagem.

Assim, esta investigação tem como objetivo identificar as disciplinas de e para o ensino da Matemática. Buscamos responder a seguinte questão: Quais e como são as disciplinas para o ensino da Matemática nas instituições públicas de Mato Grosso do Sul? E para isso apresentamos um estudo teórico sobre a formação do pedagogo, a metodologia documental desenvolvida e as análises nas próximas seções.

\section{A formação do pedagogo para ensinar matemática: referencial teórico}

O professor responsável pelos primeiros contatos com a Matemática no ambiente escolar é o pedagogo. Este profissional possui uma diversidade de atribuições e grandes possibilidades de caminhos a seguir em sua vida profissional. Desta forma, as instituições de Ensino Superior que atuam na formação de pedagogos se desdobram para prepará-los de forma eficaz em um período que normalmente é de até quatro anos. Diante do exposto, é possível ocorrer lacunas na formação inicial de professores, uma vez que este profissional pode lecionar várias disciplinas simultaneamente. E dentre elas a Matemática.

As pesquisas têm mostrado que a Matemática é uma disciplina em que uma grande parte dos alunos tem dificuldade na compreensão. Neste sentido, Ribeiro (2021) aponta que

\footnotetext{
O desempenho médio dos alunos nos exames com itens padronizados que estão sendo realizados desde a década de 1990 tem ficado muito aquém do desejado, o que comprova a necessidade de ações mais efetivas e com abordagens inovadoras tanto em termos de objetivos que se propõe alcançar como, de forma associada, de focos de discussões, pois, como os próprios resultados têm vindo a mostrar, o que se tem vindo a fazer não tem sido efetivo, nem em termos de resultados dos alunos e muito menos em termos de suas aprendizagens - associando-as a um entender o que fazem e por que o fazem a cada momento (RIBEIRO, 2021a, p. 7)
}

Desta forma, torna-se fundamental que o pedagogo adquira em sua formação um conhecimento sólido para que, assim, desenvolva um trabalho que garanta uma prática que contribua para a melhoria da qualidade das aprendizagens matemáticas dos alunos. A aprendizagem matemática está relacionada à interação entre a Matemática sistematizada cientificamente e a Matemática como atividade humana. É de total importância que os conteúdos trabalhados nas escolas se aproximem da prática cotidiana do educando.

A década de 1990 trouxe mudanças significativas no âmbito educacional. A Lei 9.394/96 (LDB) garantiu que a formação do professor da Educação Infantil e anos iniciais do Ensino Fundamental ocorresse em nível superior, o que pode ter contribuído para a melhoria no processo de ensino e aprendizagem. Porém, apesar dos avanços, ainda é preocupante os resultados avaliativos da disciplina de Matemática. 
A Resolução n. 1/2006 fixa que o curso de Pedagogia é exclusivamente uma licenciatura com formação em docência. A partir desta Resolução, consolida-se a docência como base para a formação do pedagogo. Em seu art. 4을 define que

O curso de Licenciatura em Pedagogia destina-se à formação de professores para exercer funções de magistério na Educação Infantil e nos anos iniciais do Ensino Fundamental, nos cursos de Ensino Médio, na modalidade Normal, de Educação Profissional na área de serviços e apoio escolar e em outras áreas nas quais sejam previstos conhecimentos pedagógicos. (BRASIL, 2006, p. 2)

É possível perceber que a partir desta Resolução, a docência passa a ser a função principal da formação do curso de Pedagogia e abre amplo horizonte para a formação e atuação profissional dos pedagogos. Assim, iniciam nossas reflexões sobre como é desenvolvido a formação do pedagogo para o ensino de Matemática, visando identificar quais disciplinas do currículo estão vigentes nos programas de curso de Pedagogia de instituições públicas do Mato Grosso do Sul para que ocorra essa formação.

Pesquisas indicam que existem alguns fatores que ocasionam o fracasso na disciplina de Matemática. Zacarias (2008) considera que, embora exista medo e mito sobre a Matemática, a relação entre professor e aluno está diretamente relacionada ao processo de ensino e aprendizagem. Pezzi e Marin (2017) infere que o fracasso escolar se dá pela forma como os alunos se relacionam com a disciplina. A Matemática crítica estimula a formação de um cidadão que se mantém em uma postura ativa, de reflexão. A Matemática pensada de maneira crítica está em movimento, não segue as regras da tendência tradicional que se resume em teoria e sessões de exercícios, mas se articula com o cotidiano do aluno e possibilita a inclusão de problemas e interesses vivenciados pelos educandos. A ausência da Matemática crítica que possibilite aos estudantes tomadas de decisões ao analisar e interpretar dados matemáticos no seu cotidiano contribui para o desinteresse e, consequentemente, para a dificuldade nesta disciplina. Uma metodologia baseada na repetição e memorização de conceitos, sem de fato entender o real significado, bem como sua função social, contribuem significativamente para o fracasso escolar. Neste contexto Ribeiro $(2021$, b) afirma que

Sendo um dos elementos centrais para o desenvolvimento de uma sociedade mais crítica e informada o desenvolver a capacidade e habilidade de pensar por si mesmo, cumpre-nos, enquanto professores de e que ensinamos matemática, a responsabilidade de contribuir para desenvolver algumas dimensões desse pensamento focando, especificamente, no Pensar Matematicamente. (RIBEIRO, 2021b, p. 11)

Ensinar Matemática de forma a levar o aluno a ter facilidade em compreender os conteúdos de forma crítica e reflexiva na perspectiva de entender a função social da Matemática é considerado um grande desafio, no qual o Pedagogo precisa estar disposto a enfrentar. Desta forma, Ribeiro e Policastro (2021) acrescenta que

É essencial que a escola e, necessariamente, a nossa prática matemática enquanto professores possibilitem desde a Educação Infantil oportunidades 
de aprendizagem, para que as crianças possam desenvolver, desde cedo, conhecimentos, habilidades e competências matemáticas que Ihes sejam úteis tanto para o contexto escolar quanto para entender o mundo que as rodeia e ser propositivas nos seus contextos específicos. (RIBEIRO; POLICASTRO, 2021, p.8)

De acordo com as Diretrizes Curriculares Nacionais para o Curso de Graduação em Pedagogia, Resolução no 1 , de 15 de maio de 2006, Art. 5:

O egresso do curso de Pedagogia deverá estar apto a: VI - ensinar Língua Portuguesa, Matemática, Ciências, História, Geografia, Artes, Educação Física, de forma interdisciplinar e adequada às diferentes fases do desenvolvimento humano. (BRASIL, 2006, p. 2)

Evidencia-se, portanto, que o pedagogo é responsável em trabalhar conhecimentos básicos que possam garantir a aprendizagem sólida e de qualidade a uma diversidade de grupos sociais. Neste sentido, Carvalho (2012) afirma que "Formar professores não é tarefa das mais simples, pois o profissional irá atuar, em sua maioria, em escolas com necessidades e especificidades diversas porque atendem a população com características socioeconômicas variadas" (CARVALHO, 2012, p. 34).

O processo de aprendizagem da Matemática é contínuo e sequencial, uma vez que a Matemática na escola é vista desde a Educação Infantil. A partir do Ensino Fundamental, quando se trabalha a Matemática de forma mais sistematizada, é possível perceber que a ausência de um aprendizado de determinado conteúdo matemático, compromete o desenvolvimento da aprendizagem nas etapas posteriores, podendo causar um efeito cascata. Neste sentido, torna-se importante despertar o interesse das crianças pela Matemática, desde a Educação Infantil. Nesta perspectiva Ribeiro (2021b) aponta que

A qualidade das aprendizagens matemáticas dos alunos é uma problemática antiga, que usualmente vem sendo associada essencialmente aos resultados obtidos nos testes nacionais e internacionais. No entanto, várias pesquisas mostram que, para melhorar a qualidade dessas aprendizagens e, em consequência, os resultados, o professor e o seu conhecimento assumem um papel central. Assim, é essencial que a formação de professores se foque efetivamente onde é mais necessária, de modo a possibilitar a implementação de práticas matemáticas de elevada qualidade. (RIBEIRO, 2021b, p. 7)

Curi (2004) em seus estudos já de uma década, problematiza a forma como a Matemática está sendo trabalhada nas universidades e como esta disciplina vem sendo pouco enfatizada e complementa que "[...] em alguns momentos da história, sequer havia a disciplina de Matemática nos cursos de formação de professores." (CURI, 2004, p. 76)

Nacarato (2009) também há mais de uma década, faz uma reflexão acerca dos saberes para se ensinar Matemática. Segundo o autor, o professor precisa entender os conteúdos matemáticos, e ter domínio conceitual sobre eles. O saber como trabalhar esses conteúdos e como relacionar os diferentes campos entre si e com outras disciplinas, também é de grande 
relevância. E por fim, o professor precisa ter criticidade ao utilizar os materiais que o auxiliarão nas suas aulas, principalmente em relação ao livro didático.

\section{Caminhos da investigação: metodologia}

Esta investigação tem uma abordagem qualitativa por entender que a pesquisa tem a preocupação em compreender um grupo social em razão da dificuldade dos professores pedagogos ao ensinar Matemática na Educação Infantil e nos anos iniciais do Ensino Fundamental. A metodologia utilizada foi a análise documental por meio dos Projetos Pedagógico do Curso - PPC dos cursos de Pedagogia da UEMS, UFGD e UFMS especificamente para as disciplinas de e para o ensino de Matemática.

No que diz respeito à análise documental, Ludke e André (1986) aborda que

Embora pouco explorada não só na área da educação como em outras áreas de ação social, a análise documental pode se constituir numa técnica valiosa de abordagem de dados qualitativos, seja complementando as informações obtidas por outras técnicas, seja desvelando aspectos novos de um tema ou problema [...] Os documentos [...] não são apenas uma fonte de informação contextualizada, mas surgem num determinado contexto e fornecem informações sobre esse mesmo contexto. (LUDKE; ANDRÉ, 1986, p. 38-39)

Assim, nosso objetivo nesta investigação foi identificar as disciplinas de e para o ensino de Matemática. Assim, pretendemos responder à seguinte questão: Como está ocorrendo a formação do pedagogo para o ensino de Matemática nas instituições públicas no Mato Grosso do Sul?

Com isso, buscamos todos os PPCs dos cursos de Pedagogia das universidades públicas do Mato Grosso do Sul. Conforme vemos na Quadro 1.

Quadro 1 - PPCs selecionados e analisados.

\begin{tabular}{|l|l|}
\hline Instituição & ano \\
\hline Universidade Federal da Grande Dourados - UFGD & 2019 \\
\hline Universidade Federal do Mato Grosso do Sul (UFMS) - Campus de Campo Grande & 2018 \\
\hline Universidade Estadual do Mato Grosso do Sul (UFMS) - Campus de Aquidauana & 2018 \\
\hline Universidade Estadual do Mato Grosso do Sul (UFMS) - Campus de Três Lagoas & 2018 \\
\hline Universidade Estadual de Mato Grosso do Sul (UEMS) - Maracaju & 2017 \\
\hline Universidade Estadual do Mato Grosso do Sul (UFMS) - Campus de Naviraí & 2016 \\
\hline Universidade Estadual do Mato Grosso do Sul (UFMS) - Campus de Ponta Porã & 2014 \\
\hline Universidade Estadual de Mato Grosso do Sul (UEMS) - Dourados & 2013 \\
\hline Universidade Estadual de Mato Grosso do Sul (UEMS) - Paranaíba & 2013 \\
\hline
\end{tabular}

Fonte: Autoria própria 
Fizemos a leitura na íntegra e identificamos as disciplinas de e para o ensino de Matemática. Foram analisadas as ementas das disciplinas voltadas à formação para o ensino de Matemática do pedagogo, a carga horária de cada disciplina e os referenciais teóricos utilizados como bibliografia.

\section{A formação do pedagogo para o ensino de Matemática nas instituições públicas no Mato Grosso do Sul: análises}

Ao realizarmos a leitura e a análise dos dados, os organizamos em três categorias: i) as disciplinas encontradas, ii) a carga horária, e iii) e os referenciais teóricos utilizados

i) as disciplinas encontradas

Em se tratando da área da Matemática, o curso de Pedagogia da UFMS/Campo Grande oferece uma disciplina obrigatória e uma optativa. A disciplina Fundamentos e Metodologias do Ensino da Matemática faz parte do Núcleo de Estudos Integrados com uma carga horária de 68h. Esta disciplina, obrigatória, trabalha os conteúdos e metodologias para a Educação Infantil e anos iniciais do Ensino Fundamental; as tendências no ensino da Matemática; alfabetização Matemática e língua materna; números e operações; espaço e forma, grandezas e medidas; tratamento da informação; análise de erros e avaliação. Toda esta ementa é trabalhada dentro de uma carga horária de $68 \mathrm{~h}$ o que corresponde a 2,04\% da carga horária total do curso que é de 3332 horas. Já a disciplina optativa Instrumentação do Ensino de Matemática dos anos iniciais do Ensino Fundamental tem como ementa: Materiais didáticos para o ensino de Matemática dos Anos Iniciais do Ensino Fundamental; Planejamento e avaliação de atividades didáticas em Matemática para os anos iniciais do Ensino Fundamental; Concepção e estruturação de Laboratório de Ensino de Matemática para os anos iniciais do Ensino Fundamental (inclusive para pessoas com necessidades educativas especiais). E como já foi exposto, o acadêmico tem a opção de cursar ou não esta disciplina.

O Campus Aquidauana UFMS, oferece a disciplina Fundamentos e práticas do Ensino Fundamental, com uma carga horária de 68 horas, com a seguinte ementa: Tendências da Educação Matemática. O Ensino de Matemática nos documentos oficiais (Diretrizes Curriculares, Parâmetros Curriculares Nacionais). Programas e Projetos de Ensino em Matemática. Elaboração e confecção de materiais didático-pedagógicos. Esta disciplina corresponde a 2,03\% do curso, que é de 3349 horas.

No Campus Naviraí UFMS, a Pedagogia oferece a disciplina Fundamentos e metodologias do ensino de Matemática I, com 68 horas e a seguinte ementa: Pressupostos teóricos presentes na organização dos conteúdos de Matemática na Educação Infantil no desenvolvimento dos conceitos matemáticos; Metodologias relativas aos conteúdos, tendo como eixo norteador a unidade entre teoria e prática; Relação com as áreas do conhecimento matemático propostas para a infância: números e sistema de numeração, operações aritméticas iniciais, espaço e forma (geometria), grandezas e medidas, noções de estatística e probabilidade; Atividades práticas de ensino supervisionadas. Oferece também a disciplina Fundamentos e metodologias do ensino de Matemática II com a ementa: Pressupostos teóricos presentes na organização dos conteúdos de Matemática para os anos iniciais do Ensino Fundamental no desenvolvimento dos conceitos matemáticos; Metodologias relativas 
aos conteúdos, tendo como eixo norteador a unidade entre teoria e prática a partir da abordagem das áreas do conhecimento matemático: Números e operações, Geometria, Grandezas e Medidas, Tratamento da Informação e Pensamento Algébrico; Atividades práticas de ensino supervisionadas, também com 68 horas. Além das obrigatórias, oferece uma optativa: Infância e pensamento matemático com 68 horas com a ementa: construção da matemática e sua importância para formação do pensamento matemático na criança; escrita da linguagem matemática nos aspectos sócio-históricos e psicológicos; relações entre escrita e leitura da linguagem matemática. As disciplinas obrigatórias correspondem a 4,24\% do total do curso, que é de 3201 horas.

O Campos UFMS de Ponta Porã oferece duas disciplinas obrigatórias na área da Matemática, com uma carga horária de 68 horas em cada disciplina. A disciplina Matemática Elementar tem a seguinte ementa: Discussão teórica e metodológica dos conteúdos de matemática na Educação Infantil e nos anos iniciais do Ensino Fundamental: Espaço e Forma; Números e Operações; Grandezas e Medidas; Padrões e Regularidades; Frações e Decimais. A Disciplina Fundamentos e práticas do Ensino da Matemática contém a seguinte ementa: Tendências da Educação Matemática; O Ensino de Matemática nos documentos oficiais (Diretrizes Curriculares, Parâmetros Curriculares Nacionais); Programas e Projetos de Ensino em Matemática; A utilização das novas tecnologias para o desenvolvimento do ensino e da aprendizagem; Elaboração de um artigo científico referente aos assuntos abordados na disciplina. O curso também oferece duas disciplinas optativas na área da Matemática: História da Matemática e da Educação Matemática e Introdução a Modelagem Matemática, porém, no PPC desta instituição não consta as ementas destas disciplinas. As disciplinas obrigatórias perfazem 3,86\% do total do curso, que é de 3520 horas.

O Campus UFMS de Três Lagoas oferece três disciplinas obrigatórias na área da Matemática e uma optativa. A disciplina Pressupostos Teóricos e Práticos do Ensino de Matemática para a Educação da Infância I com carga horária de 102 horas tem uma ementa que aborda nas questões teóricas: Abordagens teórico-metodológicas do processo de ensino em Matemática primando pela uma unidade entre teoria e prática na formação do futuro professor que ensinará matemática; A construção do conceito de número; Compreensão das características do sistema de numeração decimal; Significados das operações a partir dos problemas que envolvem as estruturas aditivas e multiplicativas; Conteúdos específicos dos demais campos matemáticos, a saber: Espaço e Forma, Grandezas e Medidas e Tratamento da Informação. E na prática: Apresentação da estrutura de materiais manipuláveis e proposição de atividades com escala cuisenaire, material dourado, palitos de sorvete, quadro de valor e lugar (Q.V.L), similares como sapateira, fichas escalonadas entre outros; Aplicação e discussão sobre recursos lúdicos no ensino de matemática, a saber: Jogos (Nunca Dez, Batalha das operações; Cincos; Borboleta; adivinhe o número; Tangram; Geoplano; entre outros recursos). Ainda realizam atividades dirigidas como: Resolução de problemas envolvendo as quatro operações e geometria; atividades de aplicação envolvendo diferentes métodos de elaboração do algoritmo da multiplicação e divisão. A disciplina Pressupostos Teóricos e Práticos do Ensino de Matemática para a Educação da Infância II, também com carga horária de 102 horas, tem um ementário que envolve teoria e prática. Nas questões teóricas a ementa aborda: Os conteúdos específicos de matemática na Educação Infantil e anos iniciais do ensino fundamental bem como os recursos didáticos e pedagógicos para 
ensino das mesmas; O conhecimento matemático a partir da Resolução de problemas; $A$ abordagem aos jogos; $O$ uso da calculadora e os processos de raciocínio e cálculo; Compreensão do conceito de número racional; O estudo das frações; Situações-problema que envolvam porcentagem; Identificação de tipos de problemas com raciocínio combinatório; Análise de livros didáticos. E na prática: Apresentação da estrutura de materiais manipuláveis e proposição de atividades com sólidos geométricos, blocos lógicos, disco de frações; calculadora, réguas, fitas métricas, cubos de 1 decímetro cúbico, recipientes para cálculo de volume, entre vários outros que estiverem disponíveis. Ainda realizam atividades dirigidas como: Resolução de problemas envolvendo a geometria, medidas de comprimento, volume e capacidade, superfície etc. Além de atividades de aplicação envolvendo problemas de permuta, arranjo, combinatória, produto cartesiano, porcentagem, frações mistas, impróprias, equivalentes. Neste semestre ainda realizam uma síntese com a investigação de livros didáticos utilizados pelas escolas e o acervo literário paradidático envolvendo os campos de conhecimento matemático estudados na disciplina. A disciplina optativa, Infância e pensamento matemático, com uma carga horária de 33 horas tem a seguinte ementa: Refletir sobre as diferentes concepções de ensino de Matemática e as influências destas concepções na prática do professor e na formação dos alunos; A organização do trabalho didático conforme as metodologias recomendadas pela área de Educação Matemática para Educação Infantil e anos iniciais do Ensino Fundamental. É possível perceber que as disciplinas obrigatórias perfazem $5,8 \%$ do total do curso, que é de 3485 horas.

Em relação à área da Matemática, o curso de Pedagogia da UFGD oferece uma disciplina obrigatória e uma optativa. A disciplina Currículo e Ensino de Matemática pertence ao Núcleo de Estudos Básicos, com a carga horária de $90 \mathrm{~h}$ e a seguinte ementa: Fundamentos teóricos do ensino de matemática, currículo, metodologia, recursos e avaliação. É possível observar que a carga horária desta disciplina compreende a 2,75\% da carga horária do curso que é de 3265 horas. A disciplina optativa Metodologia do Ensino de Matemática tem uma carga horária de $72 \mathrm{~h}$ e tem a seguinte ementa: Métodos, Técnicas, Linguagem e Fundamentos no Ensino de Matemática; Conteúdo e Teorias de Aprendizagem da Matemática. Mas como não é uma disciplina obrigatória, nem todos os alunos têm acesso a esse conteúdo.

Em relação à área da Matemática o PPC da UEMS Pedagogia Dourados, o curso oferece a disciplina Metodologia do Ensino da Matemática, com uma carga horária de 136 horas. Esta disciplina, de acordo com o PPC, tem o objetivo de "Aprofundar e ampliar o conhecimento matemático, especialmente em relação aos conceitos, princípios e procedimentos necessários na Educação Infantil e no Ensino Fundamental." Apresenta a seguinte ementa: Características do pensamento lógico-matemático; Fundamentos teóricos do ensino de Matemática; 0 ensino da Matemática na Educação Infantil e no Ensino Fundamental; Os conteúdos matemáticos na Educação Infantil e nos anos iniciais do Ensino Fundamental; Material didático para o ensino da Matemática. Esta disciplina corresponde a 4,09\% do total do curso, que é de 3838 horas.

O Campus de Paranaíba - UEMS oferece a disciplina Fundamentos e metodologia do ensino da Matemática, com uma carga horária de 136 horas. Tem como ementa: Explorar os conceitos fundamentais da matemática, bem como analisar os aspectos teóricos e metodológicos ao ensino e aprendizagem destes; discutir as diferentes abordagens acerca da resolução de problemas e do uso de jogos como recursos pedagógicos eficientes; Conhecer as 
pesquisas desenvolvidas na área da Educação Matemática, bem como explorar suas contribuições. Esta disciplina corresponde a 4,22\% do total do curso, que é de 2319 horas.

A Pedagogia do Campus de Maracajú/UEMS oferece a disciplina, na área da Matemática, Ensino de Matemática: conteúdo e metodologia. Segundo o PPC, um dos objetivos desta disciplina é "Aprofundar e ampliar o conhecimento matemático, especialmente em relação aos conceitos, princípios e procedimentos necessários na Educação Infantil e Ensino Fundamental." Possui a seguinte ementa: Visão histórica e epistemológica do conhecimento matemático; A função social dos conteúdos matemáticos; A Matemática no currículo, na legislação e em diferentes enfoques teóricos metodológicos; O processo de ensino e de aprendizagem dos conteúdos matemáticos na Educação Infantil e nos anos iniciais do Ensino Fundamental; Propostas metodológicas para a Matemática na Educação Infantil e nos anos iniciais do Ensino Fundamental; A avaliação da aprendizagem matemática; Material didático para o ensino da Matemática; Números e Operações: conjuntos numéricos, números racionais, divisibilidade aritmética e seus critérios, números primos, múltiplos e divisores; Espaço e Forma: características das figuras bidimensionais e tridimensionais, planificação de figuras, noção de ares e perímetro; Grandezas e Medidas: principais medidas usuais; Tratamento da Informação: características dos gráficos e tabelas, noção de combinatória. Esta disciplina tem uma carga horária de 170 horas que corresponde a 5,14\% do total do curso que é de 3302 horas.

Assim, os dados revelam poucas disciplinas de e para ensinar Matemática, além da carga menor de $5 \%$ das horas destinadas ao curso de Pedagogia. Este fato revela uma fragilidade na formação dos pedagogos, tendo em vista que para se ter uma formação adequada é preciso disciplinas de estudo e reflexão no currículo formativo do pedagogo.

Ao analisarmos as matrizes curriculares dos cursos de Pedagogia, é possível perceber que existe uma diversidade de nomenclaturas para as disciplinas na área da Matemática. Contudo, observamos que a maioria das disciplinas dá enfoque às questões relacionadas à metodologias, em detrimento aos conhecimentos específicos da área de Matemática, uma vez que os conhecimentos já deveriam ter sido adquiridos na educação básica. Porém, os estudantes da Pedagogia têm a probabilidade de ter tido uma formação matemática com algumas fragilidades no ensino regular, pois como já foi colocado, existe uma série de fatores que colabora para que a construção do conhecimento matemático seja deficiente.

Nas ementas das disciplinas ofertadas pelos cursos de Pedagogia das referidas universidades, o "como ensinar" é predominante, e cede lugar ao próprio domínio do conhecimento. É inconcebível pensar em um professor à margem deste domínio.

A partir dos dados das ementas das disciplinas, é possível inferir que as universidades têm organizado a formação matemática no curso de Pedagogia de forma insuficiente. Neste sentido, Curi (2004) em sua pesquisa ao analisar os cursos de Pedagogia, observa que

[...] os futuros professores concluem cursos de formação sem conhecimentos de conceitos matemáticos com os quais irão trabalhar, tanto no que concerne a conceitos quanto procedimentos, como também da própria linguagem matemática que utilizarão em sua prática docente. (CURI, 2004, p. 76-77) 


\section{ii) a carga horária}

Identificamos também a carga horária das disciplinas e sua relação na composição do curso. O quadro a seguir faz um comparativo da carga horária de cada disciplina com o total de horas do curso e a porcentagem de cada disciplina.

Tabela 2 - Comparativo de Carga Horária.

\begin{tabular}{|c|c|c|c|c|}
\hline INSTITUIÇÃO & DISCIPLINA & $\begin{array}{c}\text { CARGA } \\
\text { HORÁRIA } \\
\text { DA } \\
\text { DISCIPLIN } \\
\text { A }\end{array}$ & $\begin{array}{l}\text { CARGA } \\
\text { HORÁRIA } \\
\text { TOTAL DO } \\
\text { CURSO }\end{array}$ & $\begin{array}{c}\text { PORCENTAGEM } \\
\text { EM RELAÇÃO À } \\
\text { CARGA HORÁRIA } \\
\text { TOTAL }\end{array}$ \\
\hline \multirow{3}{*}{$\begin{array}{l}\text { UFMS/Campo } \\
\text { Grande }\end{array}$} & $\begin{array}{l}\text { Fundamentos e Metodologias do ensino } \\
\text { de Matemática }\end{array}$ & 68 & \multirow[t]{3}{*}{3332} & $2,04 \%$ \\
\hline & $\begin{array}{l}\text { Instrumentação do Ensino de Matemática } \\
\text { da Educação Infantil } \\
\text { (optativa) }\end{array}$ & 68 & & $2,04 \%$ \\
\hline & $\begin{array}{l}\text { Instrumentação do Ensino de Matemática } \\
\text { dos Anos Iniciais do Ensino Fundamental } \\
\text { (optativa) }\end{array}$ & 68 & & $2,04 \%$ \\
\hline $\begin{array}{l}\text { UFMS/ } \\
\text { AQUIDAUANA }\end{array}$ & $\begin{array}{l}\text { Fundamentos e práticas do ensino da } \\
\text { Matemática }\end{array}$ & 68 & 3349 & $2.03 \%$ \\
\hline \multirow[t]{3}{*}{$\begin{array}{l}\text { UFMS/ } \\
\text { NAVIRAÍ }\end{array}$} & $\begin{array}{l}\text { Fundamentos e metodologias do ensino } \\
\text { de Matemática I }\end{array}$ & 68 & \multirow[t]{3}{*}{3201} & $2,12 \%$ \\
\hline & $\begin{array}{l}\text { Fundamentos e metodologias do ensino } \\
\text { de Matemática II }\end{array}$ & 68 & & $2,12 \%$ \\
\hline & Infância e pensamento matemático & 68 & & $2,12 \%$ \\
\hline \multirow[t]{4}{*}{$\begin{array}{l}\text { UFMS/PONTA } \\
\text { PORÃ }\end{array}$} & $\begin{array}{l}\text { Fundamentos e Práticas do Ensino da } \\
\text { Matemática }\end{array}$ & 68 & \multirow{4}{*}{3520} & $1,93 \%$ \\
\hline & Matemática Elementar & 68 & & $1,93 \%$ \\
\hline & $\begin{array}{l}\text { História da Matemática e da Educação } \\
\text { Matemática }\end{array}$ & 68 & & $1,93 \%$ \\
\hline & Introdução a Modelagem Matemática & 68 & & $1,93 \%$ \\
\hline \multirow{2}{*}{$\begin{array}{l}\text { UFMS/TRÊS } \\
\text { LAGOAS }\end{array}$} & $\begin{array}{l}\text { Pressupostos Teóricos e Práticas do } \\
\text { Ensino de Matemática para a Educação da } \\
\text { Infância I }\end{array}$ & 102 & \multirow[t]{2}{*}{3485} & $2,92 \%$ \\
\hline & $\begin{array}{l}\text { Pressupostos Teóricos e Práticas do } \\
\text { Ensino de Matemática para a Educação da } \\
\text { Infância II }\end{array}$ & 102 & & $2,92 \%$ \\
\hline
\end{tabular}




\begin{tabular}{|l|l|l|l|l|}
\multirow{2}{*}{ UFGD } & Infância e Pensamento Matemático & 34 & & $0,97 \%$ \\
\hline & Currículo e Ensino de Matemática & 90 & $2,75 \%$ \\
\cline { 2 - 3 } & $\begin{array}{l}\text { Metodologia do Ensino de Matemática } \\
\text { (optativa) }\end{array}$ & 72 & $2,20 \%$ \\
\cline { 2 - 4 } $\begin{array}{l}\text { UEMS } \\
\text { (Maracaju) }\end{array}$ & $\begin{array}{l}\text { Ensino de Matemática: Conteúdo e } \\
\text { Metodologia }\end{array}$ & 170 & 3302 & $5,14 \%$ \\
\hline $\begin{array}{l}\text { UEMS } \\
\text { (Paranaíba) }\end{array}$ & $\begin{array}{l}\text { Fundamentos e Metodologias do Ensino } \\
\text { da Matemática }\end{array}$ & 136 & 2319 & 5,86 \\
\hline $\begin{array}{l}\text { UEMS } \\
\text { (DOURADOS) }\end{array}$ & Metodologia do Ensino da Matemática & 136 & 3838 & 3,54 \\
\hline
\end{tabular}

Fonte: PCCs dos cursos de Pedagogia das referidas Universidades.

O que se pode observar é que as universidades que formam pedagogos, no qual possui um vasto campo de atuação, destinam uma carga horária muito pequena para trabalhar, tanto o ensino de metodologia quanto para o desenvolvimento dos conteúdos específicos da disciplina, tão necessários para o processo de ensino e aprendizagem, na área da Matemática, para crianças. Como se pode observar, a maioria das disciplinas destina uma média de apenas $2 \%$ da sua totalidade para as disciplinas que preparam o aluno para trabalhar com a Matemática, com exceção da UEMS/Maracajú que destina 5,14\% e a UEMS/Paranaíba, que destina 5,86\% para as disciplinas que têm relação com a Matemática.

\section{iii) referenciais teóricos utilizados}

Analisamos também os referenciais teóricos utilizados para o estudo dessas disciplinas. Assim, a tabela 3 mostra os referenciais teóricos usados na bibliografia das disciplinas dos Cursos de Pedagogia:

Tabela 3 - Referenciais teóricos utilizados nas disciplinas. 


\begin{tabular}{|c|c|}
\hline Instituição & Referenciais Teóricos utilizados \\
\hline UFGD & $\begin{array}{l}\text { CURRÍCULO E ENSINO DE MATEMÁTICA } \\
\text { Bibliografia Básica: } \\
\text { TOLEDO, Marilia; TOLEDO, Mauro (1997) - KAMII, Constance (1997) - MIGUEL, Antonio; } \\
\text { MIORIM, Maria Ângela (2005) } \\
\text { Bibliografia Complementar: } \\
\text { BRASIL (1998) - BRASIL (1998) - BRASIL (2017) - NACARATO, Adair Mendes (2009) - } \\
\text { SMOLE, Kátia Cristina Stocco (1996) - NUNES, Terezinha (2005) } \\
\text { METODOLOGIA DO ENSINO DE MATEMÁTICA } \\
\text { Bibliografia Básica: } \\
\text { CARVALHO, Dione Lucchesi de (2011) - DANTE, Luiz Roberto (2010) - MAGALHÃES, de; } \\
\text { BITTAR, Marilena (2004) } \\
\text { Bibliografia Complementar: } \\
\text { AGUIAR, João Serapiã (1998) - ROSA NETO, Ernesto (1998) - SAIZ, Irma; LERNER, Delia; } \\
\text { PARRA, Cecilia (1996) - SMOLE, Kátia Cristina Stocco (1996) - TOLEDO, Marilia; TOLEDO, } \\
\text { Mauro (1997) }\end{array}$ \\
\hline $\begin{array}{l}\text { UFMS/Campo } \\
\text { Grande }\end{array}$ & $\begin{array}{l}\text { FUNDAMENTOS E METODOLOGIAS DO ENSINO DA MATEMÁTICA } \\
\text { Bibliografia Básica: } \\
\text { DANYLUK, Ocsana (2002) - PARRA, Cecília; SAIZ, Irma (2009) - LORENZATO, S. (2006) - } \\
\text { FONSECA, M. C. F. R. (2004) } \\
\text { Bibliografia Complementar: } \\
\text { PANIZZA, M. et al. (2006) - SMOLE, Kátia Cristina Stocco; DINIZ, Maria Ignez de Souza } \\
\text { Vieira (2001) - MACHADO, Nilson José (1989) } \\
\text { INSTRUMENTAÇÃO DO ENSINO DE MATEMÁTICA DOS ANOS INICIAIS DO } \\
\text { ENSINO FUNDAMENTAL } \\
\text { Bibliografia Básica: } \\
\text { CUNHA, Nylse Helena Silva; NASCIMENTO, Sandra Kraft do (2005) - BAIRRAL, Marcelo } \\
\text { Almeida (2005) - LORENZATO, Sérgio (2006) } \\
\text { Bibliografia Complementar: } \\
\text { MIGUEL, Antonio; MIORIM, Maria Ângela (2008) - MENDES, I. A. (2009) }\end{array}$ \\
\hline $\begin{array}{l}\text { UFMS/ } \\
\text { Aquidauana }\end{array}$ & $\begin{array}{l}\text { FUNDAMENTOS E PRÁTICA DO ENSINO DA MATEMÁTICA } \\
\text { Bibliografia Básica: } \\
\text { PANIZZA, M. et al. (2006) - FREITAS, José Luiz Magalhães De; BITTAR, Marilena (2004) - } \\
\text { BRASIL (1998) } \\
\text { Bibliografia Complementar: } \\
\text { NACARATO, A. M; MENGALI, B.I.s.; PASSOS, C.I.b. (2009) VAN DE WALLE, J. A (2009) - } \\
\text { CERQUETTI-ABERKANE, Francoise; BERDONNEAU, Catherine (2001) - LORENZATO, Sergio } \\
\text { (2006) }\end{array}$ \\
\hline
\end{tabular}




\begin{tabular}{|c|c|}
\hline UFMS/ Naviraí & $\begin{array}{l}\text { FUNDAMENTOS E METODOLOGIAS DO ENSINO DE MATEMÁTICA I } \\
\text { Bibliografia Básica: } \\
\text { BRASIL (1998) - LORENZATO, S. (2011) - SMOLE, K. C. S. (2003) - SMOLE, K. S.; DINIZ, M. } \\
\text { I.; CÂNDIDO, P. (2000) - SMOLE, K. S.; DINIZ, M. I.; CÂNDIDO (2000) - DANTE, L. R. (1991) } \\
\text { - JESUS, M. A. S.; FINI, L. D. T. (2005) - KAMII, C.; DEVRIES, R. (1991) - KAMII, C. (1990) - } \\
\text { TANCREDI. R. S. P (2004) } \\
\text { Bibliografia Complementar: } \\
\text { DANTE, L. R. (1991) - JESUS, M. A. S.; FINI, L. D. T. (2005) - KAMII, C.; DEVRIES, R. (1991) - } \\
\text { KAMII, C. (1990) - TANCREDI. R. S. P. (2004) } \\
\text { FUNDAMENTOS E METODOLOGIAS DO ENSINO DE MATEMÁTICA II } \\
\text { Bibliografia Básica: } \\
\text { BITTAR, M.; FREITAS, J. L. M. (2004) - BRASIL (1997) - CARRAHER, T. N.; CARRAHER, D.; } \\
\text { SCHLIEMANN, A. (1994) - PARRA, C.; SAIZ, I. (1996) } \\
\text { Bibliografia Complementar: } \\
\text { MACHADO, N. J. (1991) - MAGINA, S.; CAMPOS, T. M. M.; GATIRANA, V.; NUNES, T. } \\
\text { (2001) - NUNES, T.; CAMPOS, S. M.; BRYANT, P. (2001) - PIRES, C. M. C.; CURI, E.; } \\
\text { CAMPOS, T. M. M. (2000) } \\
\text { INFÂNCIA E PENSAMENTO MATEMÁTICO } \\
\text { NACARATO, A. M. LOPES, C. E. (2005) - PANIZZA, M (2006) - SMOLE, K. C. S. (1996) - } \\
\text { COOL, C.; MARCHESI, Á., PALACIUS, J. (2004) - KAMII, C.; DESVRIES, R. (1985) - } \\
\text { KISHIMOTO, F. M. (1994) }\end{array}$ \\
\hline $\begin{array}{l}\text { UFMS/Ponta } \\
\text { Porã }\end{array}$ & $\begin{array}{l}\text { FUNDAMENTOS E PRÁTICAS DO ENSINO DA MATEMÁTICA } \\
\text { Bibliografia Básica: } \\
\text { BRASIL (1998) - FREITAS, J.L.M.; BITTAR, (2004) - PANIZZA, M. et al. (2006) } \\
\text { Bibliografia Complementar: } \\
\text { LORENZATO, Sergio. (2006) - NACARATO, A. M; MENGALI, B.L.S.; PASSOS, C.L.B. (2009) - } \\
\text { VAN DE WALLE, J. (2009) } \\
\text { MATEMÁTICA ELEMENTAR } \\
\text { Bibliografia Básica: } \\
\text { BARBOSA, R.M. (2009) - FREITAS, J.L.M.; BITTAR, M. (2004) - KAMII, C. (1983) } \\
\text { Bibliografia Complementar: } \\
\text { BRASIL (1998) - PANIZZA, M. et al. (2006) - GRANDO, R.C.; TORICELLI, L.; NACARATO, A. } \\
\text { M. (2008) }\end{array}$ \\
\hline
\end{tabular}




\begin{tabular}{|c|c|}
\hline $\begin{array}{l}\text { UFMS/Três } \\
\text { Lagoas }\end{array}$ & $\begin{array}{l}\text { PRESSUPOSTOS TEÓRICOS E PRÁTICOS DO ENSINO DE MATEMÁTICA PARA A } \\
\text { EDUCAÇÃO DA INFÂNCIA I } \\
\text { Bibliografia Básica: } \\
\text { DANTE, Luiz Roberto (1995); GRANDO, Regina Célia. (2004) BRASIL (1998) } \\
\text { Bibliografia Complementar: } \\
\text { PAIS, Luiz Carlos. (2002-2008) - FREITAS, José Luiz Magalhães De; BITTAR, Marilena. } \\
\text { (2004) - KAMII, Constance; DECLARK, Georgia (1994) } \\
\text { PRESSUPOSTOS TEÓRICOS E PRÁTICOS DO ENSINO DE MATEMÁTICA PARA A } \\
\text { EDUCAÇÃO DA INFÂNCIA II } \\
\text { Bibliografia Básica: } \\
\text { ARRIBAS, Teresa Lleixà (2008) - PANIZZA, Mabel et al. (2006); Brasil (2001) } \\
\text { Bibliografia Complementar: } \\
\text { WEISZ, Telma; SANCHEZ, Ana (2006-2009) - NACARATO, Adair Mendes; LOPES, Celi } \\
\text { Espasandin (2009) - PONTE, João Pedro Da; BROCARDO, Joana; OLIVEIRA, Hélia (2006) - } \\
\text { BORBA, Marcelo de Carvalho; ARAÚJO, Jussara de Loiola (Orgs) (2006) } \\
\text { INFÂNCIA E PENSAMENTO MATEMÁTICO (OPTATIVA) } \\
\text { Bibliografia Básica: } \\
\text { KISHIMOTO, Tizuko Morchida (Org.). (2002) - FIORENTINI, Dario; NACARATO, Adair } \\
\text { Mendes (2005) - FIORENTINI, Dario (2003-2008) } \\
\text { Bibliografia Complementar: } \\
\text { WEISZ, Telma; SANCHEZ, Ana (2006-2009) - PANIZZA, Mabel et al. (2006) - FREITAS, José } \\
\text { Luiz Magalhães De; BITTAR, Marilena (2004) }\end{array}$ \\
\hline $\begin{array}{l}\text { UFMS/ } \\
\text { Dourados }\end{array}$ & $\begin{array}{l}\text { METODOLOGIA DO ENSINO DA MATEMÁTICA } \\
\text { Bibliografia Básica: } \\
\text { BIGODE, Antônio José Lopes; FRANT, Janete Bolite (2011) - BRASIL (1998) - BRASIL } \\
\text { (1997) - COLL, César; TEBEROSKY, Ana (2002) - SMOLE, Kátia Stocco et al. (2000) } \\
\text { Bibliografia Complementar: } \\
\text { CENTURIÓN, Marília (2006) - FONSECA, Maria da Conceição (2007) - ITACARAMBI, Ruth } \\
\text { Ribas (2010) - NACARATO, Adair Mendes; MENGALI, Brenda Leme da Silva; PASSOS, } \\
\text { Cármen Lúcia Brancaglion ( 2011) - NUNES, Terezinha et al. (2001) - PANIZZA, Mabel et } \\
\text { al. (2006) - PIROLA, Nelson Antônio; AMARO, Fernanda de Oliveira Soares Taxa (Orgs). } \\
\text { (2006) - SELVA, Ana Coelho Vieira; BORBA, Rute Elizabete Rosa (2010) - SMOLE, Kátia } \\
\text { Stocco (1996) - SMOLE, Kátia Stocco; DINIZ, Maria Ignez; CÂNDIDO, Patrícia (2003) }\end{array}$ \\
\hline $\begin{array}{l}\text { UFMS/ } \\
\text { Maracaju }\end{array}$ & $\begin{array}{l}\text { ENSINO DE MATEMÁTICA: CONTEÚDO E METODOLOGIA } \\
\text { Bibliografia Básica: } \\
\text { BRASIL (2010) - NACARATO, Adair Mendes; MENGALI, Brenda Leme da Silva; PASSOS, } \\
\text { Cármen Lúcia Brancaglion (2011) - PANIZZA, Mabel et al. (2006) } \\
\text { Bibliografia Complementar: } \\
\text { BIGODE, Antônio José Lopes; FRANT, Janete Bolite (2011) - ITACARAMBI, Ruth Ribas } \\
\text { (2010) - SELVA, Ana Coelho Vieira; BORBA, Rute Elizabete Rosa (2010) - BERNARDI, } \\
\text { Jussara, (2007) - CARVALHO, Dione Lucchesi de (2006) }\end{array}$ \\
\hline
\end{tabular}




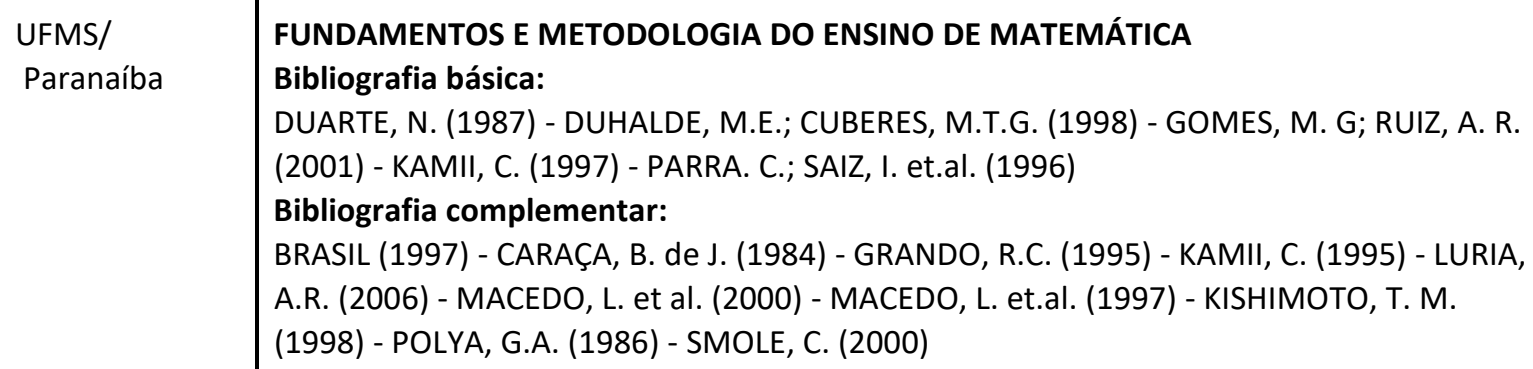

Fonte: PCCs dos cursos de Pedagogia das referidas Universidades.

Observa-se neste quadro, uma variedade de autores que, na sua maioria, contribuem significativamente para o ensino da Matemática. De modo geral, observamos que autores como a Kamii (1995) fundamentam uma formação piagetiana e as reflexões psicológicas para a aprendizagem. Percebe-se também autores destinados ao uso de metodologias lúdicas, jogos, reflexões linguísticas e de uso de materiais manipuláveis, como por exemplo: Kishimoto (1998), Bittar e Freitas (2004), Smole (1996, 2000), Panizzi (2006), Nacarato; Mengali; Passos (2009) e outros. Nota-se que há PPCs que ainda utilizam os documentos curriculares não atualizados, inferimos que em alguns casos seja recente publicação da Base Comum Curricular Nacional.

\section{Considerações finais}

Tendo em vista a importância da formação inicial dos professores pedagogos para o ensino da Matemática, esta pesquisa trouxe uma análise de como está ocorrendo a formação do pedagogo nas instituições públicas de Mato Grosso do Sul.

Com a aprovação das Diretrizes Curriculares Nacionais, em 2006, houve a definição de que a docência é a base da formação do pedagogo. Desta forma, a formação inicial se apresenta como essencial para o exercício do trabalho decente, pois é antes de tudo uma formação humana e intencional.

Esta pesquisa mostrou pouca presença de conteúdos matemáticos nos cursos de Pedagogia. A maioria das disciplinas se apresenta com caráter metodológico. O que se pode observar é que os cursos de Pedagogia pesquisados não têm como foco a formação de professores para o ensino da Matemática. Destina-se uma pequena parcela da carga horária do curso para a metodologia do ensino da Matemática em detrimento dos conteúdos específicos da Matemática, tão necessários para a formação do futuro professor. Devido ao pequeno número de aulas destinadas à Matemática, é pouco provável realizar um aprofundamento necessário para uma aprendizagem satisfatória nos cursos de Pedagogia. Porém, o simples fato de ampliar a carga horária pode não significar a garantia na qualidade do ensino da Matemática. A formação de pedagogos deve ser concebida como prática social concreta.

A busca por uma formação inicial que proporcione uma efetiva articulação entre os saberes explorados no curso e sua aplicabilidade na escola, torna-se urgente. É necessária a compreensão de que não basta aplicar metodologias bem elaboradas se esta não estiver bem articulada com a realidade dos alunos. Também torna-se urgente compreender que o professor deve ter domínio dos fundamentos históricos e epistemológicos e dos conceitos 
teóricos-metodológicos. Neste sentido, o curso de Pedagogia precisa evidenciar o quê, o como e para que ensinar.

Com isso, com base nos PPCs analisados, levando em conta as ementas das disciplinas e a carga horária de cada disciplina, pode-se perceber que o curso de Pedagogia precisa desenvolver estratégias para superar as fragilidades em relação ao ensino da Matemática. Desta forma, os currículos precisam trazer elementos que possam garantir um efetivo domínio dos conteúdos quanto uma metodologia eficiente, e para além disso, garantir a reflexão crítica sobre a prática pedagógica diária.

\section{Referências}

BRASIL. Resolução CNE/CP № 1/2006. Diretrizes Curriculares Nacionais para o Curso de Graduação em Pedagogia, licenciatura. Brasília, 2006.

BRASIL. LEI № 9.394/1996. Diretrizes e Bases da Educação Nacional. Brasília, 1996.

CARVALHO, Mercedes. Estágio na licenciatura em Matemática: Observações nos anos iniciais. Petrópolis, RJ: Vozes, 2012.

CURI, Edda. Formação de professores polivalentes: uma análise do conhecimento para ensinar Matemática e de crenças e atitudes que interferem na constituição desses conhecimentos. 2004. Tese (Doutorado em Educação Matemática) - Faculdade de Educação Matemática, PUC-SP, São Paulo, 2004.

LIBÂNEO, José Carlos. Pedagogia e pedagogos, para quê? 6ạ ed. São Paulo: Cortez, 2002.

LUDKE, Menga; ANDRÉ, Marli Eliza Dalmago Afonso. Pesquisa em educação: abordagens qualitativas. São Paulo: EDU 1996 (Coleção Temas Básicos de Educação e Ensino).

NACARATO, Adair Mendes (Org.). A Matemática nos anos iniciais do ensino fundamental: tecendo fios do ensinar e do aprender. Belo Horizonte: Autêntica Editora, 2009.

PEZZI, Fernanda Aparecida Szareski; MARIN, Angela Helena. Fracasso escolar na educação básica: revisão sistemática da literatura. Temas em Psicologia, v. 25, n.1, p. 1-15, 2017.

RIBEIRO, Miguel. Brincar com intencionalidade matemática: números, suas representações e entendimentos. 1 ed. Curitiba: Appris, 2021a.

RIBEIRO, Miguel. Pensar matematicamente envolvendo diferentes formas de ver e de contar e as conexões com o pensamento algébrico. Campinas: CIEspMat Pesquisa e Formação, 2021b (Coleção CIEspMat - Formação).

RIBEIRO, Miguel; POLICASTRO, Milena. As medidas e as especificidades do conhecimento do professor para que os alunos aprendam matemática com significado. Curitiba: CRV, 2021. 
TANURI, Leonor Maria. História na formação de professores. Revista Brasileira de Educação. São Paulo, n. 14, 2000. Disponível em:

http://www.amped.org.br/rbe/rbedigital/RBDE14_06_LEONOR_MARIA_TANURI.pdf.

ZACARIAS, Sandra Maria Zen. A Matemática e o fracasso escolar: medo, mito ou dificuldade. UNOESTE: Presidente Prudente, 2008. (Dissertação de Mestrado). 